\title{
Intravascular ultrasound in patients with acute pulmonary embolism after treatment with intravenous urokinase and high-dose heparin
}

\author{
Günter Görge, Stefan Schuster, Junbo Ge, Jürgen Meyer, Raimund Erbel
}

\begin{abstract}
Objective-To compare the diagnostic value of intravascular ultrasound (IVUS) with angiography in patients with pulmonary embolism.

Design-Open, prospective clinical study. Setting-Two university hospitals.

Patients-Angiography and IVUS were used in 11 patients (5 men) (mean (SD) age 50 (18) years) with acute pulmonary embolism.

Interventions-At a mean (SD) of 6 (4) hours after thrombolytic therapy with urokinase and full-dose heparin, all patients underwent pulmonary artery angiography. Then $3.5 \mathrm{~F}$ mechanical, 20 or $30 \mathrm{MHz}$ IVUS catheters were advanced into the pulmonary circulation.
\end{abstract}

Main outcome measures-The pulmonary circulation was studied by both methods to detect the presence of thrombus, and a modified Miller score (assessing perfusion defects only and not velocity of flow) was used to quantify the angiographic images.

Results-The modified Miller score was mean (SD) $7.4(2.3)$ points. 168 pulmonary artery segments (diameter range 2-14 $\mathrm{mm}$ ) were studied by angiography and IVUS. On angiography, seven segments showed complete obstruction and 49 partial obstruction; 112 were normal. Two distinct types of thrombus formation were found by IVUS. Type A thrombus only partly adhered to the wall but otherwise was mobile and type $B$ predominantly adhered to the wall. IVUS confirmed all seven angiographically complete obstructions but missed three $(6 \%)$ of the 49 partial occlusions. Forty (87\%) of the remaining 46 segments had type $A$ thrombus and six (13\%) type $B$. IVUS indicated a thrombus in $38(34 \%)$ of the 112 angiographically normal segments; 20 (53\%) showed a type A pattern and $18(47 \%)$ a type $B$ pattern $(P<0.001)$. Conclusion-IVUS was more sensitive than angiography in detecting thrombus but the clinical impact of this finding is not clear as yet.

(Heart 1997;77:73-77)
Keywords: intravascular ultrasound; pulmonary embolism; pulmonary hypertension; thrombolytic therapy

In acute pulmonary embolism, rapid diagnosis and prompt and appropriate treatment are crucial to outcome. ${ }^{12}$ The diagnostic approach has changed over the past two decades, mainly owing to the introduction of non-invasive tests such as ventilation-perfusion scans and echocardiography. ${ }^{3}$ Transthoracic echocardiography enables us to determine non-invasively the pulmonary artery pressure and the right ventricular volumes and function. Transoesophageal echocardiography has the additional advantage of identifying proximal pulmonary artery embolism in some patients. ${ }^{4-10}$ Thus patients identified as having haemodynamically relevant embolic events can be treated early with full-dose heparin and, if necessary, with thrombolytic agents. ${ }^{11-14}$

In patients with suspected pulmonary embolism, angiography is an invasive method that gives a rapid and complete image of the entire pulmonary circulation, yet it need not be performed in all patients. Moreover, the injection of ionic, high-osmolality contrast material puts critically ill patients at increased risk; non-ionic low-osmolality contrast agents are usually well tolerated. ${ }^{15} 16$ However, the imaging of partially occluded vessel segments by angiography has been liable to misinterpretation. ${ }^{16}$

Intravascular ultrasound (IVUS) is a new technique that images the lumen and the vessel wall by means of very small ultrasound probes. It is likely to be useful in the diagnosis of abnormalities of the pulmonary circulation. ${ }^{1718}$ Our group was among the first to show the diagnostic value of IVUS in a patient with acute pulmonary embolism. ${ }^{19}$ Tapson et al reported their initial experience with IVUS in a canine model of pulmonary embolism and in a limited number of patients, as did Ricou et al in patients with recurrent thromboembolic disease. ${ }^{20-22}$ The aim of our study was to investigate further the feasibility, accuracy, and safety of IVUS in patients after thrombolytic treatment for acute pulmonary embolism, and to compare the results with angiography. 
Clinical and haemodymanic measurements (obtained during angiography), and demographic data on 11 patients studied prospectively

\begin{tabular}{|c|c|c|c|c|c|c|c|c|c|c|c|c|c|}
\hline Case & Sex & Age & $\begin{array}{l}B S A \\
\left(m^{2}\right)\end{array}$ & $\begin{array}{l}H R \\
\left(\text { min }^{-1}\right)\end{array}$ & $\begin{array}{l}P A \text { syst } \\
(\mathrm{mm} \mathrm{Hg})\end{array}$ & $\begin{array}{l}P A \text { dias } \\
(\mathrm{mm} \mathrm{Hg})\end{array}$ & $\begin{array}{l}P A \text { mean } \\
(m m \mathrm{Hg})\end{array}$ & $\begin{array}{l}P C W \\
(m m \mathrm{Hg})\end{array}$ & $\begin{array}{l}C I \\
\left(l^{\left.-1 / m^{2}\right)}\right.\end{array}$ & $\begin{array}{l}\text { Pulmonary } \\
\text { resistance } \\
\left(\text { dyn.s. } \mathrm{cm}^{-5}\right)\end{array}$ & $\begin{array}{l}P O^{2} \\
(m m H g)\end{array}$ & $\begin{array}{l}\mathrm{PCO}^{2} \\
(\mathrm{~mm} \mathrm{Hg})\end{array}$ & $\begin{array}{l}\text { Clinical } \\
\text { outcome }\end{array}$ \\
\hline 1 & F & 20 & $1 \cdot 80$ & 112 & 26 & 12 & $16 \cdot 7$ & 7 & $2 \cdot 5$ & 172 & 58 & 33 & Alive \\
\hline 2 & $\mathbf{F}$ & 30 & 1.95 & 100 & 45 & 18 & $27 \cdot 0$ & 10 & $1 \cdot 7$ & 410 & 61 & 29 & Alive \\
\hline 3 & $\mathrm{~F}$ & 62 & 1.60 & 90 & 31 & 15 & $20 \cdot 3$ & 8 & $3 \cdot 2$ & 193 & 66 & 34 & Alive \\
\hline 4 & $\mathbf{M}$ & 57 & $1 \cdot 80$ & 124 & 51 & 29 & $36 \cdot 3$ & 5 & $2 \cdot 8$ & 497 & 60 & 37 & Alive \\
\hline 5 & M & 65 & $2 \cdot 45$ & 54 & 60 & 15 & $30 \cdot 0$ & 7 & $2 \cdot 4$ & 313 & 72 & 45 & Alive \\
\hline 6 & $\mathbf{F}$ & 18 & 1.70 & 68 & 24 & 14 & $17 \cdot 3$ & 5 & $3 \cdot 2$ & 181 & 65 & 41 & Alive \\
\hline 7 & $\mathbf{F}$ & 60 & 1.90 & 103 & 52 & 25 & $34 \cdot 0$ & 11 & $2 \cdot \overline{8}$ & 346 & 80 & 43 & Alive \\
\hline 8 & $\mathbf{M}$ & 54 & $2 \cdot 10$ & 105 & 44 & 16 & $25 \cdot 3$ & 5 & $2 \cdot 8$ & 277 & 57 & 34 & Alive \\
\hline 9 & $\mathbf{M}$ & 47 & 1.60 & 66 & 56 & 23 & $34 \cdot 0$ & 8 & $2 \cdot 1$ & 619 & 55 & 32 & Surgery \\
\hline 10 & $\mathbf{F}$ & 65 & 1.65 & 102 & 47 & 18 & $27 \cdot 7$ & 9 & $1 \cdot 7$ & 532 & 50 & 48 & Alive \\
\hline 11 & $\mathbf{M}$ & 73 & 1.75 & 88 & 38 & 16 & $23 \cdot 3$ & 9 & $2 \cdot 9$ & 226 & 81 & 29 & Alive \\
\hline $\begin{array}{l}\text { Mean } \\
\text { (SD) }\end{array}$ & & $50(18)$ & $1.85(0.24)$ & $92(20 \cdot 4)$ & $43.09(11.45)$ & $18.27(4.97)$ & $26.55(6 \cdot 42)$ & $7 \cdot 6(2 \cdot 0)$ & $2 \cdot 6(0.5)$ & $342(147)$ & $64(10)$ & $37(6)$ & \\
\hline
\end{tabular}

One patient (case 9) had recurrent thrombembolic events and underwent successful thromboendarterectomy. All patients were discharged alive and well. BSA, body surface area; PA, pulmonary artery; syst, systolic; diast, diastolic; PCW, pulmonary capillary wedge pressure; CI, cardiac index.

\section{Patients and methods}

PATIENTS

Patients with the diagnosis of acute pulmonary embolism based on clinical signs such as shortness of breath, heart rate $>100$ beats/min, systolic blood pressure $<110 \mathrm{~mm}$ $\mathrm{Hg}$, and the additional finding of right ventricular overload during echocardiography, or of a positive ventilation-perfusion scan, and who were suitable for thrombolytic therapy, were entered prospectively in our study over a 23 month period. The patients underwent right heart catheterisation and angiography of their pulmonary arteries mean (SD) 6 (4) hours after treatment with three million units of urokinase in one hour, and a bolus injection of 10000 units of heparin, followed by continuous infusion for 48 hours. All patients were awake and gave their informed consent for the thrombolytic therapy, angiography, and the IVUS study. The use of IVUS catheters was approved by the local ethics committees and the study complied with the Declaration of Helsinki. All patients with vascular access from the legs had an angiographic study or ultrasonic examination of their femoral and pelvic veins before puncture to rule out thrombus formation.

METHODS

Angiography was performed using a Siemens HICOR, BICOR, or MICOR system. A pigtail catheter was advanced through an introducing sheath placed in a femoral or brachial vein, and selectively positioned in the right

Figure 1 Comparison of diameter dimensions obtained by angiography and intravascular ultrasound in angiographically normal pulmonary arteries (Altman-Bland plot). ${ }^{23}$ Standard error (SD) was $0.6 \mathrm{~mm}$, and IVUS underestimated diameters larger than $5 \mathrm{~mm}$ in comparison with angiography. $(n=33)$

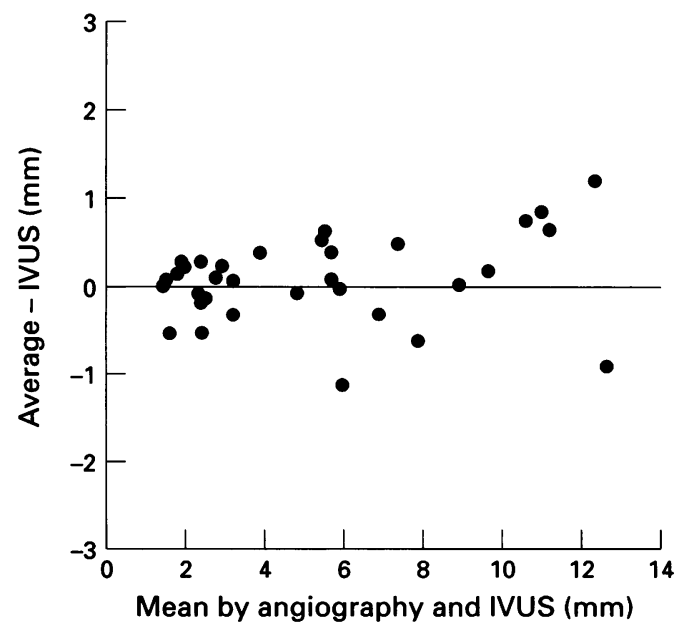

and left pulmonary arteries. Non-ionic contrast material $(45-55 \mathrm{ml}$ in each side, $10-14 \mathrm{ml} / \mathrm{s}$ ) was injected selectively into the left and right pulmonary circulation. Pulmonary capillary wedge pressure and pressures in the pulmonary artery, right ventricle, and right atrium were measured with $7.5 \mathrm{~F}$ Swan-Ganz catheters.

For the IVUS study we used $3.5 \mathrm{~F}$, mechanical, 20 or $30 \mathrm{MHz}$, monorail echo transducers (Boston Scientific, Waterton, MA, USA) connected to a Hewlett Packard Sonos or Diasonics echo system with S-VHS video recording.

\section{ANALYSIS}

The severity of embolisation in the pulmonary circulation was judged from the angiographic findings using the Miller score to assess embolic involvement (but not the effect on pulmonary contrast flow) as described in detail elsewhere. ${ }^{11}$ The diameter of the pulmonary arteries was calculated from the angiograms using the pigtail catheter for calibration.

The Miller score was calculated by two physicians blinded to the results of the other colleague. The IVUS images were also analysed by two cardiologists to determine the minimal and maximal lumen diameters and the nature of thrombus formation (complete obstruction, wall adherent, or partially mobile echodense structures). The clinical course of the patients was followed until discharge from the hospital.

\section{STATISTICAL ANALYSIS}

All statistics were calculated using a commercially available and validated program (SAS, release 6.04, SAS Institute; Cary, NC, USA) for MS-DOS computers. Values are given as a mean (SD). The pulmonary artery diameter measurements by angiography and IVUS were plotted by the graphical technique proposed by Bland and Altman. ${ }^{23}$ The presence or absence of a thrombus was compared using a chi-square table.

\section{Results}

Eleven patients were studied by both methods. The patient's characteristics, their haemodynamic variables during the invasive study, and 
Figure 2 (A)

Intravascular appearance of acute pulmonary

embolism. Non-circular,

soft partly mobile thrombus

(type A pattern) in

positions 2-4. Complete

obstruction in position 1.

(B) Typical example of the

intravascular appearance

of an old, recanalised

thrombus (type B pattern,

wall adherent, non-

mobile), confirmed by

surgery.
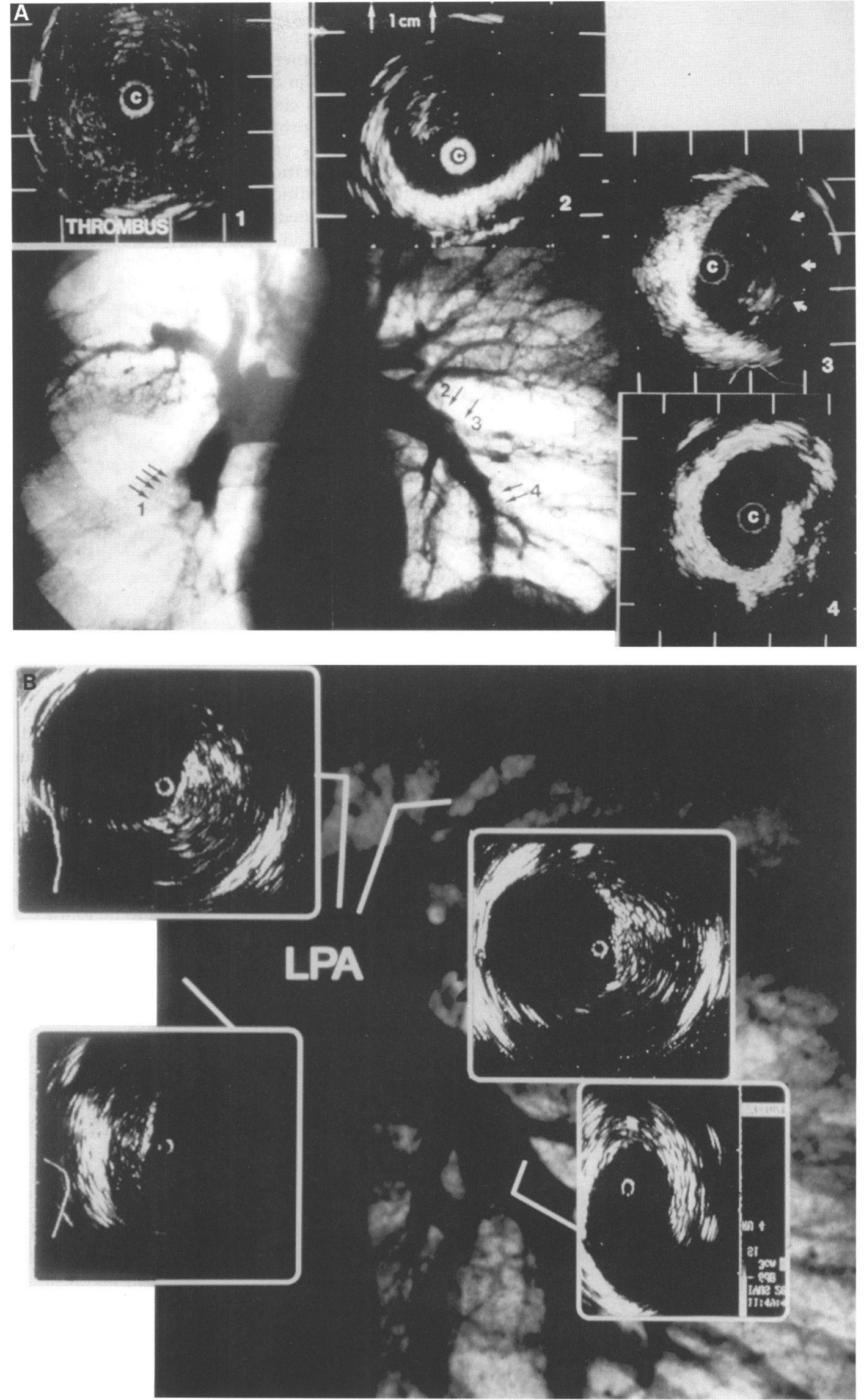

their clinical outcomes are summarised in the table. All patients were discharged alive and well, and there were no adverse events attributable to the thrombolytic therapy, angiography, or IVUS examination.

The Miller index ranged from 4 to 12 points (mean (SD) $7 \cdot 4(2 \cdot 3)$ ). A total of 168 pulmonary artery segments were studied by both methods. On the basis of the angiographic results, seven segments showed complete obstruction, 49 partial obstruction and angiographic signs typical of thrombus formation, 
and 112 segments were normal. There was good agreement between angiography and IVUS measurements of luminal diameter in vessels ranging from $3 \mathrm{~mm}$ to $14 \mathrm{~mm}$ in diameter (fig 1). In nine of 11 patients no circumferential image was obtained in the proximal pulmonary arteries because of the eccentric position and limited far-field penetration of the 20 or $30 \mathrm{MHz}$ catheters. In addition to complete obstruction, IVUS identified two additional types of thrombus formation. The first type (type A) was thrombus partially adherent to the vessel wall, but otherwise mobile (fig 2A). The second type was thrombus completely adherent to the vessel wall, either circumferential or in a half moon shape (type B) (fig 2B).

Though the correlation between IVUS and angiography was $100 \%$ in seven segments with complete obstructions, there were differences both in angiographically normal and partially occluded vessel segments. Three $(6 \%)$ of the 49 angiographically partially occluded vessel segments showed no signs of thrombus formation during IVUS; probably because the IVUS examination was performed after angiography and the thrombus may have resolved. Forty $(87 \%)$ of the remaining 46 segments showed type A thrombus during IVUS and six (13\%) showed a type B appearance.

IVUS revealed thrombus in $38(34 \%)$ of the 112 angiographically normal segments. Twenty (53\%) showed a type A pattern and $18(47 \%)$ a type B pattern $(\mathrm{P}<0.001)$.

In general, IVUS had a higher sensitivity for thrombus formation than angiography, mainly for wall adherent but also for partially wall adherent and mobile thrombi. Of the $38 \mathrm{seg}$ ments with thrombus confirmed by IVUS but negative angiographically, 14 were found in the proximal pulmonary artery, 15 in a first level branch, and nine in a second level branch.

The additional fluoroscopy time for the IVUS study was $3.75(0.8)$ minutes (range 2-7.5 minutes). No IVUS related complications occurred. All patients were discharged alive and well. In one patient, recurrent pulmonary embolic events with persistent pulmonary hypertension was diagnosed. He underwent successful thromboendarterectomy later.

\section{Discussion}

The present paper describes the experience with both angiography and IVUS in patients with acute pulmonary embolism after thrombolytic therapy. The main finding was that IVUS revealed thrombus formation in $38 \%$ of angiographically normal segments. Furthermore, two different types of pulmonary thrombus formation could be identified: type A, a partially wall adherent, but otherwise mobile thrombus; and type B, a thrombus most of which is attached to the vessel wall. In addition, thrombus formation was found in the inferior vena cava in two patients in whom it was not detected by other techniques. Our findings concerning the feasibility and safety of
IVUS in patients with pulmonary hypertension accord with the findings of Ricou et al in patients with recurrent thromboembolic disease and with the initial experiences of Tapson et $a l$ and Scott et al..$^{20-2224}$

\section{PRESENT LIMITATIONS}

The IVUS catheters presently available are designed for use in the coronary arteries and are not steerable. Because of limited steerability they were often in eccentric position, with the consequence that the diameters could not be determined accurately in all segments of the pulmonary circulation. The first experience with a new steerable IVUS catheter showed that this design may overcome this limitation, as may the forward viewing crystals. 2526

Although the sensitivity of IVUS for the detection of thrombus was superior to that of angiography, even high frequency intravascular ultrasound may miss very fresh thrombus formation.

\section{CLINICAL IMPLICATIONS}

The main diagnostic advantage of IVUS over angiography was that it revealed more residual thrombus formation. However, the clinical implication of this finding is unclear and in the present study the IVUS findings did not affect the clinical consequences. IVUS has already been shown to be superior to angiography in the coronary circulation. Angiography is a contour method and thus limited to imaging the contrast-filled lumen. ${ }^{27}$ It may therefore overlook recanalised or predominantly wall adherent thrombus with a regular surface. The haemodynamic significance of residual, angiographically overlooked thrombi and their clinical implication are as yet not known, nonetheless in theory IVUS may allow such lesions to be followed up.

1 McIntyre KM, Sasahara AA. The hemodynamic response to pulmonary embolism in patients without prior cardiopulmonary disease. $A m \mathcal{F}$ Cardiol 1974;28:288-94.

2 Stein PD, Terrin ML, Hales CA, Palevsky HI, Saltzman HA, Weg JG. Clinical, laboratory, roentgenographic, and electrocardiographic findings in patients with acute pulelectrocardiographic findings in patients with acute pul-
monary embolism and no pre-existing cardiac or pulmonary disease. Chest 1991;100:598-603.

3 Coates G. Isotope lung imaging. Curr Opin Radiol 1992;4: 79-86.

4 Dale JE. Clinical diagnosis of acute pulmonary embolismwhen should a V/Q scan be ordered? Chest 1991;100: 5:1185-6.

5 Stein PD, Coleman RE, Gottschalk A, Saltzman HA, Terrin ML, Weg JG. Diagnostic ultility of ventilation/ perfusion lung scans in acute pulmonary embolism is not diminished by pre-existing cardiac or pulmonary disease. Chest 1991;100:604-6.

6 Kasper W, Meinertz T, Kersting F, Löllgen H, Limbourg $P$, Just $\mathbf{H}$. Echocardiography in assessing acute pulmonary hypertension due to pulmonary embolism. $\mathrm{Am} \mathcal{F}$ Cardiol 1980;45:567-72.

7 Yock PG, Popp RL. Noninvasive estimation of right ventricular systolic pressure by Doppler ultrasound in patients with tricuspid regurgitation. Circulation 1984; 70:657-62.

8 Kitabatake A, Inoue M, Asao M, Masuyama T, Tanouch J, Morita $\mathrm{T}$, et al. Noninvasive evaluation of pulmonary hypertension by a pulsed Doppler technique. Circulation 1983;68:302-9.

9 Nixdorff U, Erbel R, Drexler M, Meyer J. Detection of thrombembolus of the right pulmonary artery by transesophageal two-dimensional echocardiography. $A m \AA$ Cardiol 1988;61:448-9.

10 Wittlich N, Erbel R, Eichler A, Schuster S, Jakob $H$, Iversen $S$, et al. Detection of central pulmonary artery thrombemboli by transesophageal echocardiography in thrombemboli by transesophageal echocardiography in patients with severe pulmonar

11 Miller GAH, Sutton GC, Kerr IH, Gibson RV, Honey M. Comparison of streptokinase and heparin in treatment of 
isolated acute massive pulmonary embolism. $\mathrm{Br} \mathrm{Med} \mathcal{F}$ $1971 ; 2: 681-4$

12 Schwarz F, Stehr H, Zimmermann R, Manthey J, Kübler $\mathrm{W}$. Sustained improvement of pulmonary hemodynamics in patients at rest and during exercise after thrombolytic treatment of massive pulmonary embolism. Circulation 1985;71:1:117-23.

13 PIOPED Investigators. Tissue plasminogen activator for the treatment of acute pulmonary embolism. Chest 1990; 97:528-33.
the treatment

14 Tilsner V. Thrombolytic therapy in fulminant pulmonary thromboembolism. Thorac Cardiovasc Surg 1991;39: 357-9.

15 Saeed M, Braun SD, Cohan RH, Sussman SK, Illescas FF, Perlmutt LM, et al. Pulmonary angiography with iopamidol: patient comfort, image quality, and hemodynamics. Radiology 1987;165:324-49.

16 Benotti JR, Grossmann W. Pulmonary angiography. In: Grossman W, ed. Cardiac catheterization and angiography. 3rd ed. Philadelphia, USA: Lea and Febiger, 1985: 213-26.

17 Pandian NG, Weintraub A, Kreis A, Schwartz SL, Konstam MA, Salem DN. Intracardiac, intravascular, two-dimensional, high-frequency ultrasound imaging of pulmonary artery and its branches in humans and ani-
mals. Circulation 1990;81:2007-12.

18 Tobis JM, Mallery J, Mahon D, Lehmann K, Zalesky $P$, Griffith $\mathrm{J}$, et al. Intravascular ultrasound imaging of human coronary arteries in vivo. Analysis of tissue characterizations with comparison to in vitro histological specimens. Circulation 1991;83:913-26.

19 Görge G, Erbel R, Schuster S, Ge J, Meyer J. Intravascular ultrasound in diagnosis of acute pulmonary embolism. Lancet 1991;337:623-4.

20 Tapson VF, Davidson CJ, Gurbel PA, Sheikh KH, Kisslo KB, Stack RS. Rapid and accurate diagnosis of pulmonary emboli in a canine model using intravascular ultrasound imaging. Chest 1991;100:1410-3.

21 Ricou F, Nicod PH, Moser KM, Peterson KL. Catheterbased intravascular ultrasound imaging of chronic thromboembolic pulmonary disease. Am $\mathcal{f}$ Cardiol 1991;67: 749-52.

22 Tapson VF, Davidson CJ, Kisslo KB, Stack RS. Rapid visualization of massive pulmonary emboli utilizing intravascular ultrasound. Chest 1994;105:888-90.

23 Bland JM, Altman DG. Statistical methods for assessing agreement between two methods of clinical measurement. Lancet 1986; i:307-10.

24 Scott PJ, Essop AR, al-Ashab W, Deaner A, Parsons J, Williams G. Imaging of pulmonary vascular disease by intravascular ultrasound. Int 7 Card Imaging 1993;9: 179-84.

25 Görge G, Ge J, Haude M, Baumgart D, Buck T, Erbel R Initial experience with a steerable intravascular ultrasound catheter in the aorta and pulmonary artery. $\operatorname{Am} \mathcal{F}$ Card Imaging 1995;9:180-4.

26 Evans $\mathrm{JL}, \mathrm{Ng} \mathrm{KH}$, Vonesh MJ, Kramer BL, Meyers SN, Mills TA, et al. Arterial imaging with a new forwardviewing intravascular ultrasound catheter, I. Initial studies. Circulation 1994;89:712-7.

27 Waller BF, Pinkerton CA, Slack JD. Intravascular ultrasound: a histological study of vessels during life. The new "gold standard" for vascular imaging. Circulation 1992;85:2305-10. 